\title{
LOS PRINCIPIOS DISPOSITIVO Y APORTACIÓN DE PARTE EN EL PROCESO LABORAL. SU INCIDENCIA EN LA INICIATIVA PROBATORIA JUDICIAL
}

\author{
RAúl Audito Fernández TOledo* \\ Abogado
}

RESUMEN: El objetivo del presente trabajo es demostrar que los principios dispositivo y aportación de parte, a pesar de no estar expresamente mencionados entre los principios formativos del proceso en el artículo 425 del Código del Trabajo, sí se configuran como principios en el proceso laboral. Para comprobar este aserto, se examinarán las disposiciones legales que dan configuración normativa a los principios mencionados.

En efecto, se pretende hacer un completo análisis de los principios en cuestión, delimitando claramente sus manifestaciones o contenido, para así evitar toda confusión entre ellos y con otros principios formativos del proceso laboral. Ello porque una falsa concepción de estos principios ha llevado a parte de la doctrina y jurisprudencia a sostener una opinión errada de los mismos, rechazando la iniciativa probatoria judicial por vulnerar el principio dispositivo.

Nosotros haremos notar que tal opinión es equivocada, a partir de una delimitación conceptual clara entre los principios objeto de nuestro análisis, siendo perfectamente compatible la vigencia del principio dispositivo y la iniciativa probatoria judicial.

Palabras clave: Principio dispositivo, principio de aportación de parte, iniciativa probatoria judicial

\begin{abstract}
The purpose of this paper is to demonstrate that the dispositive and party provision principles, even though not expressly mentioned among the formative principles of the process in Article 425 of the Labor Code, they are actually configured as principles in the labor procedure. In order to verify this assertion, the laws which give regulatory configuration to the above principles will be examined. Indeed, it is our intention to make a complete analysis of the principles involved, clearly delimiting their manifestations and content in order to avoid any confusion between them and other formative principles of the labor procedure. This is so because a false conception of these principles has led part of the doctrine and jurisprudence to hold a wrong concept of them, thus rejecting the initiative for judicial probation for considering it as a violation of the dispositive principle.

We will make note that such view is wrong, from a clear conceptual demarcation between the principles that are being analyzed, being as it is perfectly possible to reconcile both the dispositive and party provision principles.
\end{abstract}

Key words: Dispositive principle, party provision principle, judicial proof iniciative

\section{PRINCIPIO DISPOSITIVO Y PRINCIPIO DE APORTACIÓN DE PARTE. DELIMITACIÓN CONCEPTUAL}

Desde finales del siglo XIX y buena parte del siglo XX, época de codificaciones en Europa y América, en que la desconfianza hacia los poderes estatales se refleja en una restrictiva interpretación de la posible iniciativa de la autoridad judicial respecto de los intereses

\footnotetext{
Abogado asociado al área de Derecho del Trabajo y Seguridad Social del Estudio Jurídico Philippi, Irarrázabal, Pulido \& Brunner. Este trabajo forma parte del libro titulado Las Facultades y Deberes del Juez en Materia Probatoria en el Proceso Laboral. Análisis Crítico. Santiago: Editorial PuntoLex - Thomson Reuters, 2011.
} 
privados discutido en el proceso civil (incluyendo el laboral), entendido como opuesto al proceso penal, es concebido como Sache der Parteien, es decir, como cosas de partes. Esta concepción presupone en palabras de Schwab, dejar la responsabilidad de la marcha del proceso a las partes ${ }^{1}$. Por otro lado, se explica este dominio predominante de las partes en la marcha del proceso, por ser considerado este como un mero apéndice del derecho material discutido, era el ropaje exterior del derecho planteado en juicio que no merecía ni siquiera consideración dogmática; a nadie podía ocurrírsele que ese ropaje tuviera una naturaleza distinta de la figura que debía cubrir.

Otro escollo que debía ser superado para eliminar este estado de confusión, y reconocer el carácter público del proceso, era lograr la distinción entre la relación jurídica de derecho material que corresponde a los particulares, y la relación jurídica procesal, de carácter esencialmente público, que estaban subsumidas en una sola, considerada de carácter privado. Ello explica la negativa a toda iniciativa del juez en la proposición y práctica de medios de prueba no ofrecidos por las partes y el aumento de sus deberes en la dirección del proceso. Las partes eran las únicas dueñas de la actividad procesal y del contenido del proceso, quedando el juez relegado a la figura de juez impasible, convidado de piedra como lo denominó el profesor Lascano. Se produce en consecuencia, una confusión entre el poder de disposición del objeto litigioso de naturaleza privada, y el dominio respecto del proceso ${ }^{2}$, de naturaleza esencialmente pública, por ser el instrumento por medio del cual los tribunales ejercen la función pública denominada "Jurisdicción".

Fue la doctrina alemana la que resolvió este estado de confusión, limitando el concepto de principio dispositivo (Dispositionsprinzip) al dominio por los litigantes del interés privado, y el de aportación de parte (Verhandlungsmaxime) a la introducción y prueba de los hechos en el proceso ${ }^{3,4}$. Esta distinción fue acogida posteriormente por la doctrina italiana ${ }^{5}$, luego por la española ${ }^{6}$ y finalmente por los países latinoamericanos seguidores de las corrientes doctrinarias europeas.

Este delineamiento de conceptos no solo ha quedado claro en la doctrina, sino también en las legislaciones procesales civiles, procesales laborales y en general en todos los

\footnotetext{
1 Opinión recogida por BAUR, Fritz, "Liberalización y Socialización del Proceso Civil", en: Revista de Derecho Procesal Iberoamericana, Tomo II-III, p. 317. Madrid, 1972.

2 Picó I Junoy, Joan, El Derecho a la Prueba en el Proceso Civil. Barcelona: Editorial José María Bosch Editor S.A., 1996, p. 209.

3 Ibid., p. 209.

4 Los antónimos o principios contrapuestos son: del Dispositivo (Dispositionsprinzip) el Principio de Oficialidad (Offzialprinzip) y del Principio de Aportación de Parte (Verhandlungsmaxime) el Principio de Investigación de Oficio (Untersuchungsmaxime).

5 Con respecto a la doctrina italiana es necesario formular una observación de orden terminológico: la mayoría de los autores reservan los nombres de principio dispositivo en sentido estricto, material o propio o principio de la demanda al que nosotros denominamos principio dispositivo, y los de principio dispositivo, principio dispositivo en sentido lato, procesal o impropio, principio de disponibilidad de la prueba al principio de aportación de parte. Al respecto vid. especialmente, CARNACINI, Tito, "Tutela Jurisdiccional y Técnica del Proceso", en: Revista de la Facultad de Derecho Universidad Nacional Autónoma de México, Tomo III, No 12, 1953, pp. 97-182. Ciudad de México: Universidad Nacional Autónoma de México.

6 En la doctrina procesal de lengua española pueden consultarse los estudios de FAIRÉN GUiLLÉN, Víctor, "Para la elaboración de una doctrina general de los principios del procedimiento", en: Anuario de Derecho Civil, pp. 1345 y ss. Madrid, 1948; Cordón Moreno, Faustino, "En Torno a los Poderes de Dirección del Juez Civil", en: Revista de Derecho Privado, pp. 809 y ss. Madrid, 1979, entre otros.
} 
procesos que han derivado del proceso civil más moderno. Advirtiendo, empero, que ello ha sido consagrado con distintos matices, pero coincidiendo en la esencia de la misma.

Ahora bien, para deslindar claramente estos principios cabe preguntarse ¿cuáles son las manifestaciones del principio dispositivo?, ¿ en qué consiste el principio de aportación de parte? ¿Están consagrados ambos en el proceso laboral chileno? Las respuestas no pueden ser dadas conjuntamente, siendo necesario seguir un orden de ideas que desarrollaremos a continuación.

Como cuestión previa, cabe señalar que ambos son considerados principios del proceso $^{7}$ de carácter técnico jurídico o bien principios específicos, queriendo poner de relieve que ambos predominarían en el proceso civil entendido en sentido amplio.

\section{CONSAGRACIÓN LEGISLATIVA DE LOS PRINCIPIOS DISPOSITIVO Y APORTACIÓN DE PARTE}

La importancia de los principios dispositivo y de aportación de parte es incuestionable, toda vez que la gran mayoría de los procesos ha entregado a las partes la carga de aportar los hechos que constituyen los fundamentos de sus acciones y excepciones y las pruebas de esos hechos, cuestiones que a grandes rasgos configuran las sustancia de tales principios, debiendo el juzgador, al ejercer sus facultades y cumplir sus deberes, respetar las manifestaciones de dichos principios.

Ahora bien, nuestro legislador procesal laboral, siguiendo probablemente a la Ley No 19.968 que creó los Tribunales de Familia y a las legislaciones extranjeras, mencionó expresamente los principios formativos del proceso en el artículo 425 del Código del Trabajo, para desarrollarlos en los artículos siguientes. Sin embargo, entre ellos, no se menciona a los principios dispositivo y de aportación de parte, lo que llevaría afirmar a primera vista que por no estar mencionados en el artículo 425, no estarían consagrados en el proceso laboral, debiendo desconocérseles su calidad de principios formativos del proceso, con todas las consecuencias que derivan de no ser considerados principios. Esta opinión importa reconocer un carácter taxativo a la enumeración de principios que hace el artículo 425 del Código Laboral.

Sin embargo, al contrario de lo sostenido en el párrafo anterior, la conclusión nuestra es la contraria. El hecho de no estar mencionado expresamente en la ley, no significa que el legislador los haya desconocido, por el contrario, ha consagrado diversos artículos que son evidentes manifestaciones de los principios que nos ocupan, reconociéndolos, por tanto, implícitamente. En otras palabras, el legislador laboral consagró los principios dispositivo y de aportación de parte implícitamente, afirmación que se funda en los siguientes argumentos:

a) Las expresiones de que se sirve el legislador en el artículo 425, nos dan a entender que la enumeración de principios formativos no es taxativa, sino meramente enunciativa. En efecto, dice: "Los procedimientos del trabajo serán orales, públicos y concentrados. Primarán en ellos...", no empleando palabras como: "solo son", "únicamente", que sí darían a entender que el número de principios es cerrado, taxativo.

En este sentido María Victoria Berzosa citado por CarocCa PéreZ, Alex, Manual de Derecho Procesal. Tomo I. Santiago: Editorial LexisNexis, 2003, p. 23. 
b) No aceptar los mencionados principios es desconocer la naturaleza misma de los derechos e intereses subjetivos que se disputan en el proceso laboral, puesto que los principios que nos ocupan son la manifestación de estos derechos en el ámbito procesal.

c) El principio dispositivo tiene como fundamento directo el derecho de propiedad, que se configura como una garantía fundamental en nuestra Constitución Política de la República, por tanto, desconocer dicho principio importa vulnerar la Constitución misma.

d) Finalmente, diversas disposiciones legales del proceso laboral demuestran que tales principios no fueron olvidados por el legislador, sino, por el contrario, considerados claramente.

En consecuencia, en los párrafos siguientes se verán cómo se configuraron estos principios en la normativa laboral y cuál es su importancia.

\section{EL PRINCIPIO DISPOSITIVO Y SUS MANIFESTACIONES}

Se puede decir que consiste en la disponibilidad que los litigantes tienen sobre el interés privado y sobre la conveniencia o no de acudir al órgano jurisdiccional, pretendiendo su satisfacción, en la medida que lo estimen oportuno ${ }^{8}$. Por ello, pueden considerarse manifestaciones o notas esenciales de este principio, las siguientes:

A) El inicio de la actividad jurisdiccional a instancia de parte, de acuerdo a los aforismos nemo iudex sine actore y ne procedat iudex ex oficio, siendo la demanda el instrumento idóneo para ello. Tal manifestación se encuentra consagrada en numerosas disposiciones de nuestro Código del Trabajo, como el artículo 429, que comienza diciendo: "el tribunal una vez reclamada su intervención en forma legal(...)". Artículo que debe ser complementado con los artículos 446 (Del Procedimiento de Aplicación General), el cual dice en su encabezado: "la demanda se interpondrá por escrito(...)"; 486 (Del Procedimiento de de Tutela Laboral), cuando señala: "Cualquier trabajador... que invocando un derecho o interés legítimo, considere lesionados derechos fundamentales en el ámbito de las relaciones jurídicas cuyo conocimiento corresponde a la jurisdicción laboral, podrá requerir su tutela por la vía de este procedimiento(...)” y el artículo 499 (Del Procedimiento Monitorio) que en su inciso $1^{\circ}$ expresa: "Si no se produjere conciliación entre las partes o esta fuere parcial, como asimismo en el caso que el reclamado no concurra al comparendo, el trabajador podrá interponer demanda ante el juez del trabajo competente, dentro del plazo establecido en los artículos 168 y 201 de este Código, según corresponda".

Ahora bien, el hacer valer un derecho en vía jurisdiccional es un modo de disponer del mismo, y por consiguiente, el condicionar la tutela jurisdiccional a la petición del interesado es una lógica consecuencia de la autonomía negocial reconocida al particular sobre la propia esfera jurídica?

\footnotetext{
Picó I JUNOY, Joan, op. cit (n. 2), p. 212.

9 Calamandrei, Piero, Instituciones de Derecho Procesal Civil. Tomo I. Buenos Aires: Ediciones Jurídicas Europa-América (EJEA), 1962, p. 397.
} 
Los litigios no son tales o no interesan al Estado sino cuando trascienden al público por una manifestación de voluntad de uno de los interesados por lo menos, solicitando que sea resuelto por el órgano jurisdiccional. Mientras la diferencia u oposición de intereses se mantenga entre las partes en un ámbito de tranquilidad y silencio, el orden jurídico no sufre alteración alguna, y para el Estado no puede haber conflicto que resolver. Por consiguiente, el conocimiento que este llegara a tener particular y directamente de una desinteligencia en los negocios y contratos, no podría autorizar su intervención para formar un proceso, porque ello importaría crear o dar vida a un conflicto que antes no existía o existía solo en potencia, dado que solo puede haber proceso cuando hay litis $^{10}$; solo la demanda es manifestación de la existencia de un litigio y petición de solución del mismo. Se respeta así el derecho subjetivo, pues permitir que el juez inicie de oficio un proceso, repugna las bases fundamentales de un Estado de Derecho, vulnerando el derecho de propiedad.

Es cierto que existen ciertos derechos y situaciones jurídicas que trascienden el solo interés de las partes, afectando o interesando a otras personas, al Estado y en general a la colectividad, como pueden ser los derechos laborales netamente patrimoniales e inherentes a la persona del trabajador y los derechos previsionales, entre otros, que podrían justificar el inicio del proceso de propia iniciativa del juez, pero ello importaría desconocer la esencia misma de la actividad jurisdiccional que define y da fisonomía propia al proceso, no pudiendo el órgano jurisdiccional ser juez y parte al mismo tiempo. En tales casos, debe encomendarse a órganos distintos del juez la tarea de iniciar los procesos, pues concentrar las funciones de juzgar y demandar en una misma persona es imposible, ya que son funciones psicológicamente incompatibles. Así en nuestro derecho, a pesar de la trascendencia de los derechos laborales, los procesos únicamente pueden ser iniciados por los particulares, como hemos visto, solo que con un matiz; en el caso de los trabajadores que cumplen ciertos requisitos, gozan del privilegio de pobreza, teniendo asistencia judicial gratuita a través de la Corporación de Asistencia Judicial, órgano del Estado, pero aun así, esta solo actúa como colaboradora de los trabajadores, siendo ellos los que deciden poner en movimiento la actividad jurisdiccional, no pudiendo ser sustituida su iniciativa por nadie, al ser los titulares de los derechos subjetivos.

Sin embargo, existe en una situación una atenuación de esta manifestación del principio dispositivo. En el Procedimiento de Tutela Laboral, si bien el trabajador puede ejercer la acción, las organizaciones sindicales también puede iniciar dicho procedimiento, en representación de sus afiliados, debiendo cumplir los mismos presupuestos que el trabajador (artículo 486 del Código del Trabajo).

Por otra parte, cabe señalar que esta manifestación del principio dispositivo no solo rige en primera instancia, sino también en materia de recursos procesales, no existiendo recurso alguno que pueda ser iniciado de oficio por el tribunal por las razones ya dadas. De ahí, que al revisar los artículos 474 al 484 del Código del Trabajo, que regulan los recursos que las partes pueden interponer contra las resoluciones judiciales, no hay precepto alguno

10 Lascano, David, "El Principio Dispositivo en el Proceso Moderno", en: Revista de Derecho Procesal Argentina, Volumen II, p. 4. Buenos Aires, 1951. 
que permita concluir que el juez pueda interponer un recurso, pudiendo hacerlo solo las partes agraviadas.

Esta manifestación del principio en cuestión no ha sido vulnerado por la ley procesal laboral en ninguno de sus procedimientos, ya que es de la esencia del derecho subjetivo que se discute en el litigo, con una fuerte raigambre constitucional. La única norma que a primera vista puede considerarse como contraria a esta manifestación es el artículo 463 del Código del Trabajo, a propósito del cumplimiento de las sentencias y los títulos ejecutivos laborales, cuando señala: "La tramitación de los títulos ejecutivos laborales se desarrollará de oficio y por escrito por el tribunal, dictándose al efecto las resoluciones y ordenándose las diligencias que sean necesarias para ello". Sin embargo, un examen profundo sobre la cuestión nos lleva a concluir que no infringe el principio dispositivo, toda vez que la ejecución al menos de la sentencia judicial, a diferencia del procedimiento ejecutivo reglamentado en el Código de Procedimiento Civil, no se ha estructurado como un procedimiento, sino que es una cuestión accesoria a los procedimientos laborales destinados a la formación de los títulos ejecutivos ${ }^{11}$. De este modo, son una continuación de aquellos, que solo terminan con la ejecución del título ejecutivo obtenido, y el juez como tiene el deber de impulsar el procedimiento de oficio, está obligado a iniciar la ejecución de los títulos de oficio, sin que ello constituya ir contra el principio que nos ocupa.

B) La determinación del objeto del proceso únicamente por los litigantes (causa petendi y petitum). Las partes durante una de las etapas del proceso deben ponerse de acuerdo sobre los hechos que admiten y precisar los que desean discutir y probar, a fin de que el debate quede definitivamente fijado. La demanda (sea reconvencional o no) y la contestación de la demanda constituyen las únicas dos oportunidades en que las partes pueden hacer alegaciones relativas al fondo del asunto.

Los artículos 452 y 453 No 1 del Código del Trabajo regulan esta situación: si el demandado admite los hechos afirmados por el actor en su demanda o algunos de ellos, en las distintas hipótesis que las normas contemplan, el juez debe tenerlos por ciertos en la sentencia; del mismo modo, si el demandante admite los hechos que fundamentan las excepciones opuestas por el demandado al contestar el traslado conferido, el juez debe conformarse a ellos no pudiendo desconocerlos. En ambos casos el litigio se limita a los hechos controvertidos, fijados por el juez en la resolución que recibe la causa a prueba. Por otra parte, si el demandado se allana a la demanda o a una parte de la misma, termina la controversia o solo continúa en la parte que no se produjo el allanamiento.

Esta manifestación es también una consecuencia del reconocimiento del derecho subjetivo. Mal podría avenirse un reconocimiento inicial otorgado por el ordenamiento jurídico al derecho subjetivo, con la posibilidad de que el tribunal pueda cambiar a su antojo el contenido de la contienda judicial. Por eso las alegaciones de las partes deben determinar y limitar siempre el contenido de la decisión, son ellas las que indican las pretensiones sobre las cuales debe pronunciarse el sentenciador, a través de los actos de alegación.

11 Principalmente la sentencia judicial. 
C) La congruencia de las resoluciones judiciales con las pretensiones de las partes, resultando con plena vigencia el brocardo ne eat iudex ultra (o extra) petita partium. El artículo $459^{12}$ del Código del Trabajo, situado bajo el párrafo que tiene como epígrafe "Del Procedimiento de Aplicación General", prescribe:

"la sentencia definitiva deberá contener:

3. Una síntesis de los hechos y de las alegaciones de las partes:...

6. La resolución de las cuestiones sometidas a la decisión del tribunal, con expresa determinación de las sumas que ordene pagar o las bases necesarias para su liquidación, si ello fuere procedente...”.

Asimismo el artículo 495 del mismo cuerpo legal, en lo pertinente, consagra claramente el principio de congruencia. El juez no solo no puede proveer si antes no ha habido alguien que se lo haya pedido, sino que, además, al proveer, debe mantenerse dentro del tema planteado por las partes, en el sentido de que al indagar si existen las condiciones para aceptar la demanda, debe tomar en consideración solamente los hechos alegados por las partes, y debe, además, limitarse a conceder o denegar, en base a ellos la providencia pedida, sin poder indagar de oficio si eventualmente sería más apropiada, respecto de los mismos, una providencia diferente ${ }^{13}$. En otros términos, el magistrado debe estarse al mérito del proceso, salvo que un precepto legal específico le faculte para fallar de oficio, independientemente de las peticiones de las partes en juicio.

De vulnerar el juez inferior esta manifestación del principio dispositivo, es procedente principalmente el recurso de nulidad, como lo prescribe claramente el artículo 478 del Código del Trabajo:

"el recurso de nulidad procederá, además:(...)

a) Cuando la sentencia se hubiere dictado con omisión de cualquiera de los requisitos establecidos en los artículos 459, 495 ó 501, inciso final, de este Código, según corresponda; contuviese decisiones contradictorias; otorgare más allá de lo pedido por las partes, o se extendiere a puntos no sometidos a la decisión del tribunal, sin perjuicio de las facultades para fallar de oficio que la ley expresamente otorgue (...)".

D) La finalización de la actividad jurisdiccional por voluntad exclusiva de los litigantes, quienes pueden disponer libremente tanto de la res in iudicium deductae, mediante la transacción (artículo 426 del Código del Trabajo), el allanamiento (artículo 453 No 1 inciso $8^{\circ}$ del Código del Trabajo) o la conciliación (artículo 453 No 2 del Código del Trabajo); como de la continuación del proceso a través del desistimiento de la demanda, que es plena-

\footnotetext{
12 Este artículo es aplicable a la sentencia definitiva dictada en el Procedimiento de Tutela Laboral, por ser el Procedimiento de Aplicación General de carácter supletorio del Procedimientos de Tutela Laboral, en virtud de lo dispuesto en el artículo 432 inciso $2^{\circ}$ del Código del Trabajo. Tratándose del Procedimiento Monitorio, el artículo 501 inciso final dispone que la sentencia definitiva que se pronuncie en la audiencia única de contestación, conciliación y prueba, cuando hubiere lugar a ella, debe cumplir con lo prescrito en el No 6 del artículo 459 del Código del Trabajo, pero no con el No 3 del mismo precepto, lo que nos lleva a concluir que el principio de congruencia está consagrado en todos los procedimiento judiciales laborales.

13 Calamandrei, Piero, op. cit. (n. 9), p. 403.
} 
mente aplicable al proceso laboral, siempre que no contravenga la irrenunciabilidad de los derechos laborales, cuando esta sea procedente.

Si bien esta concreción del principio dispositivo tiene plena vigencia en el proceso laboral, sufre una cierta atenuación a consecuencia de la naturaleza de los intereses discutidos, los cuales si bien son subjetivos, son también sociales, es decir, interesan a otras personas, y en general a la colectividad, y es en este carácter que el juez debe fundarse para evitar que una disponibilidad de tales derechos puedan traducirse en una renuncia de los mismos prohibida por la ley o perjudicial para terceros. Por la misma razón no opera el abandono del procedimiento en el proceso laboral (artículo 429 Código del Trabajo), plenamente aplicable en cambio en el proceso civil.

\section{FUNDAMENTO DEL PRINCIPIO DISPOSITIVO}

El principio dispositivo, a diferencia de otros grandes principios del proceso o del procedimiento, no tiene una consagración legal y constitucional expresa que permita reforzar su protección en un proceso determinado. Sin embargo, siendo una proyección de los derechos e intereses subjetivos discutidos por las partes litigantes en el proceso, donde las diversas manifestaciones del principio dispositivo no son más que actos de ejercicio potestativo del derecho o interés discutido en el proceso, forzoso es concluir que es una concreción del derecho subjetivo controvertido. Ahora bien, es sabido que el derecho de propiedad se encuentra reconocido expresamente en el artículo 19 No 24 de la Constitución Política de la República como una garantía constitucional, asegurando a todas las personas dicho derecho sobre todas las cosas corporales e incorporales. De esta forma, existiendo propiedad sobre los derechos subjetivos y sus facultades, existen poderosos argumentos para estimar que el principio dispositivo encuentra su fundamento principalmente en el derecho de propiedad.

Así, en opinión de la doctrina mayoritaria, el fundamento del principio dispositivo se encuentra en la propia estructura del modelo económico y jurídico acogido por nuestro ordenamiento jurídico, especialmente por la Constitución Política de la República, en que se reconoce a todas las personas el derecho a la propiedad privada (artículo 19 No 24), la libertad de emprendimiento (artículo 19 No 21) y la libertad de adquirir cualquier clase de bienes, salvo ciertas excepciones (artículo 19 No 23). De esta forma, opta por un modelo que distingue claramente entre intereses privados y públicos, y la admisión de un amplio margen a la autonomía de la voluntad y a la iniciativa de los particulares. Mientras se mantenga esta distinción debe seguir imperando el principio dispositivo en el proceso laboral, pues, no obstante, el particular interés que el Estado tiene por los derechos laborales y previsionales como representante de la colectividad, no privan a estos de su carácter de subjetivos, a pesar de ciertas limitaciones y resguardos que pesan sobre ellos. Sostener lo contrario, significaría admitir que el individuo y sus derechos son instrumentos puestos al servicio del Estado y sus objetivos, tal como sucedió en las legislaciones de los países socialistas de Europa oriental cuando se encontraban bajo la influencia de la ex URSS ${ }^{14}$.

\footnotetext{
14 Ver en esta materia para el proceso civil Hunter AmpUero, Iván, "El Principio Dispositivo y Los Poderes del Juez", en: Revista de Derecho Facultad de Derecho Pontificia Universidad Católica de Valparaíso, Tomo XXXV, pp. 152 y 153. Valparaíso: Pontificia Universidad Católica de Valparaíso, 20 semestre 2010.
} 


\section{CONTENIDO DEL PRINCIPIO DE APORTACIÓN DE PARTE O PRINCIPIO DISPOSITIVO EN SU VERTIENTE PROCESAL}

En cuanto a la terminología empleada para referirse a este principio, no hay unanimidad en la doctrina, algunos lo llaman "principio dispositivo en sentido lato, procesal o impropio" y otros "principio de aportación de parte". Nosotros sin desconocer la disparidad de denominaciones emplearemos la última expresión, por una razón práctica, cual es evitar confusiones con el principio dispositivo, donde estuvo subsumido por siglos, pero advirtiendo que no importan las denominaciones, ya que estas no determinan a las instituciones jurídicas, sino que lo hace su contenido.

En lo que respecta al contenido de este principio, se limita, como hemos apuntado, a la introducción y prueba en el proceso del material fáctico. En consecuencia, aparecen como manifestaciones de este principio el que los litigantes tienen que alegar los datos o elementos fácticos de la realidad discutida en el proceso, distintos a los hechos esenciales que configuran la causa petendi, pues estos, como hemos indicado, al integrar el objeto del proceso, deben ser alegados necesariamente por las partes en virtud del principio dispositivo y no del de aportación de parte ${ }^{15}$. Por tanto, nos referimos a los motivadores de la estimación de la demanda o, en su caso, de su desestimación, si nos situamos en la perspectiva del demandado, que aun correspondiendo también a las partes, encuentran su fundamento en el principio de aportación de parte ${ }^{16}$. La regla iudex iudecare debet secundum allegata et probata partium expresa en toda su extensión el mencionado principio.

La generalidad de los ordenamientos procesales ha consagrado el principio de aportación de parte, no siendo la excepción el nuestro, sin perjuicio de los diversos matices que experimenta en los distintos procesos, dependiendo del interés que tenga el Estado en el litigio.

En el proceso laboral, este principio se encuentra consagrado principalmente a nuestro entender en los artículos 446 No 4 y 452 incisos $2^{\circ}$ y $4^{\circ}$ del Código del Trabajo, que aluden a los hechos estimativos de la demanda y su contestación, respectivamente, y en el artículo 453 No 4 del mismo Código, en cuanto a la posibilidad de introducir pruebas que verifiquen las afirmaciones fácticas controvertidas, sustanciales y pertinentes.

Ahora bien, si el poder predominante de las partes en la proposición de las pruebas no es una consecuencia necesaria del principio dispositivo, cabe preguntarse ¿cuál es el fundamento que las leyes procesales pongan en manos de las partes todo lo relativo a la recolección de las pruebas, haciendo excepcional la iniciativa probatoria judicial ex officio? La respuesta que se dé a esta pregunta es fundamental para aumentar o excluir la iniciativa probatoria del juez.

Hay quienes piensan ${ }^{17}$ que la atribución a las partes de la facultad de aportar pruebas al proceso constituye una derivación de sus derechos subjetivos, cuya tutela ellas reclaman

15 Opinión sustentada por María Victoria Berzosa, citada por PiCÓ I JUNOY, Joan, op. cit (n. 2), p. 215.

16 La doctrina no es unánime en cuanto al contenido del principio de aportación de parte, algunos se pronuncian por el contenido que hemos expuesto y otros solamente lo limitan a la proposición y práctica de los medios de prueba, en este sentido CORdón MOREnO, Faustino, op. cit. (n. 6), p. 811.

17 Así lo deja entrever VALDÉs HuECHE, Remberto, “El proceso. La imparcialidad. La concepción unitaria del proceso. La Constitución Política y los Tratados de Derechos Humanos", en: Revista de Derecho del Consejo de Defensa del Estado, No 12 , p. 128. Santiago, 2004. 
ante la autoridad judicial. En tal sentido, siendo las pruebas, o mejor su aportación, una manifestación del propio derecho subjetivo, resulta inadmisible un sistema en el cual las pruebas puedan ser traídas al debate por el propio órgano jurisdiccional ${ }^{18}$. Esta tesis no resiste un riguroso análisis científico, pues los errores en que se funda se localizan con gran facilidad, confunde el objeto litigioso con el proceso mismo, en el que aquellos se dirimen, y como todos sabemos esa teoría ya ha sido abandonada por todos o la gran mayoría de los autores. Que duda cabe que el objeto del proceso pertenece al dominio de las partes, como consecuencia de ser una manifestación de los derechos subjetivos, y a través de ellos del principio dispositivo, pero las pruebas no tienen este carácter, sino que pertenecen a un principio totalmente distinto, el de aportación de parte, por tanto, participan de su naturaleza.

La respuesta a esta interrogante debe buscarse en otra parte. Es evidente que el proceso como toda institución regulada por el derecho, debe ser organizado sobre ciertas normas que obedezcan a las reglas supremas de la vida social; y que, en ciertos aspectos, la llamada naturaleza de las cosas es la mejor guía para conocer las limitaciones a que debe estar sometido todo ensayo de regulación normativa ${ }^{19}$. El derecho al regular el proceso tiene presente la inidoneidad del juez en buscar los elementos de convicción que sean necesarios para decidir la situación controvertida sometida a su decisión. Las relaciones laborales muchas veces suceden en un contexto doméstico donde es imposible o al menos difícil que el órgano jurisdiccional pueda recolectar las pruebas, por ello, como dice Liebman, la ley no tiene mucha fe en que el juez pueda llegar al descubrimiento de la verdad por su propia iniciativa ${ }^{20}$.

Compartiendo opinión con Rodríguez, creemos que como el juez se encuentra frente a esas limitaciones, nada mejor que la ley disponga que las partes colaboren con él en la tarea de suministrarle los elementos probatorios que son necesarios para formar su convicción. Es así que surge la carga de la prueba como fórmula mediante la cual las partes se convierten en portadores de estos elementos, sin los cuales el juez no podría comprobar la conformidad de las alegaciones con la verdad, "es decir, tal como han sucedido los hechos alegados en el mundo exterior" 21 .

Mientras en el campo de las alegaciones, la recolección de los hechos constitutivos del conflicto debe ser encomendada a las partes por razones de necesidad, que impiden que las cosas puedan ocurrir de otra manera, en el campo de las pruebas prima una razón de conveniencia, la cual aconseja que sean los interesados quienes proporcionen las pruebas tendientes a demostrar las afirmaciones contenidas en la demanda y en la contestación ${ }^{22}$. Estas razones de oportunidad y conveniencia se concretan en las mayores garantías que ofrece la defensa de los derechos subjetivos privados remitida a los particulares, y en la necesidad de

\footnotetext{
18 En este sentido Hugo Alsina, citado por Rodríguez Urraca, José, Autoridad del Juez y Principio Dispositivo. ValenciaVenezuela: Universidad de Carobobo, Instituto de Derecho Privado y Comparado, 1968, p. 123.

19 Rodríguez Urraca, José, op. cit. (n. 18), p. 124.

20 Citado por Rodríguez UrRacA, José, op. cit. (n. 18), p. 125.

21 Rodríguez URRACA, José, op. cit. (n. 18), p. 125. "La carga de la prueba debemos entenderla en este momento en su doble manifestación. Por una parte asoma como una facultad, pues quien la tiene, solo puede por regla general aportar pruebas al proceso, por otro lado, tiene el tinte de deber, en sentido, de que quien no la asume poseyéndola ve rechazada su pretensión”.

22 En este sentido CarnelutTI, Francesco, Derecho y Proceso. Napoli-Italia: Morando Ediciones, 1958, p. 97.
} 
separar las funciones de investigar y juzgar como paso necesario para garantizar la imparcialidad del juez ${ }^{23}$.

Por otra parte, reforzando la argumentación desarrollada, la aportación de pruebas a instancia de parte preponderantemente, tiene un fundamento constitucional, en el derecho a la prueba que tiene toda persona ${ }^{24}$. Si se les reconoce a los particulares la posibilidad de activar la jurisdicción para obtener la tutela de sus derechos a través de la demanda o denuncia, debe garantizársele los medios necesarios para obtener la satisfacción de sus pretensiones, a lo cual contribuye el derecho a la prueba que integra el debido proceso consagrado en el artículo 19 No 3 inciso 5o de la Constitución Política de la República. A través de este derecho las partes tienen la posibilidad de proponer los medios de pruebas que sean necesarios para lograr el convencimiento del juez de que lo alegado por ellas es lo que ha sucedido en la realidad, y obtener por tanto una sentencia favorable.

El principio de aportación de parte tiene un carácter técnico, que responde a un particular modo de concebir el desarrollo del proceso jurisdiccional, en que la iniciativa de los jueces se constriñe en gran medida a la voluntad de las partes. El atribuir un carácter técnico a este principio no significa que sea inmune a concepciones políticas. De hecho, suele relacionarse con el principio dispositivo, indicándose que, como norma general, el proceso inspirado por el citado principio lo está igualmente por el de aportación de parte ${ }^{25}$.

\section{IMPORTANCIA DE LA DISTINCIÓN ENTRE EL PRINCIPIO DISPOSITIVO Y PRINCIPIO DE APORTACIÓN DE PARTE}

La diferencia entre ambos principios ha sido de gran importancia para justificar el aumento de facultades-deberes del juez en la proposición de medios probatorios no ofrecidos por las partes. Así como indica Satta, mientras el legislador no puede, sin comprometer el carácter disponible del interés discutido en el proceso laboral ${ }^{26}$, consentir al juez tutelar dicho interés en ausencia de demanda de parte o extralimitarse en tal tutela más allá de lo dispuesto por los litigantes, puede sustraerles el poder monopolístico de la iniciativa probatoria, incrementando, viceversa, los poderes del juez ${ }^{27}$.

Por otra parte, al no ser el monopolio de las partes en orden a la proposición de las pruebas una consecuencia necesaria del principio dispositivo, ni por lo tanto, de su fundamento, el derecho de propiedad en general, queda desvirtuada la objeción a la iniciativa probatoria judicial, que señala que el otorgar dicha iniciativa probatoria a los jueces se vulnera el principio dispositivo. Por ello, la doctrina ha buscado limitar la iniciativa judicial recurriendo a otros argumentos ${ }^{28}$.

23 Cordón Moreno, Faustino, op. cit. (n. 6), p. 811

24 Ver en esta materia Fernández Toledo, Raúl, Las Facultades y Deberes del Juez en Materia Probatoria en el Proceso Laboral. Análisis Crítico. Santiago: Editorial PuntoLex - Thomson Reuters, 2011, pp. 163-173.

25 PICÓ I JUNOY, Joan, op. cit (n. 2), pp. 217-218.

26 La expresión en cursiva es nuestra.

27 Citado por Picó I JUnOY, Joan, op. cit (n. 2), p. 219.

28 Ver un resumen de las distintas posiciones sobre la posibilidad que el órgano jurisdiccional puede proponer pruebas independiente de las ofrecidas por las partes en FERNÁNDEZ TOLEDO, Raúl, op. cit. (n. 24), pp. 44-61. 


\section{PRINCIPIO DE APORTACIÓN DE PARTE E INICIATIVA PROBATORIA JUDICIAL}

La ideología social surgida en el siglo pasado y desarrollada en el presente, trajo consigo el fenómeno de la socialización del proceso, que comenzó primeramente en el proceso laboral, por el manifiesto interés de la colectividad en los conflictos laborales, para expandirse posteriormente a todos los procesos donde se discutían intereses privados. Con el objeto de incorporar a los clásicos principios liberales determinadas exigencias del Estado Social de Derecho, se pone de manifiesto la distinción entre objeto del proceso y proceso mismo, cual es el instrumento idóneo para alcanzar la efectiva y real tutela por parte del Estado de los intereses litigiosos.

Una de las consecuencias más relevantes de la publicitación del proceso se concreta, como indica Picó I Junoy, en el hecho de que sin discutir la vigencia del principio dispositivo, pues la estructura de los derechos subjetivos predominantemente privados lo impide 29 , va a ponerse en tela de juicio el de aportación de parte, al menos, por lo que respecta al reparto de funciones entre el juez y los litigantes, indicándose, que si bien los litigantes son libres de disponer de los interese deducidos en juicio, o sea el objeto del proceso, no lo son respecto del proceso mismo, al concebirse no solo como un instrumento dirigido a la tutela jurisdiccional de derechos privados, sino, además, como instrumento de la función pública del Estado, llamada jurisdicción, al valerse esta de aquel para el mejor cumplimiento de su objetivo, esto es, el reestablecimiento del imperio del derecho, con objeto de alcanzar "el bienestar social" o el "rápido restablecimiento de la paz jurídica" 30 . Por ello, muchas legislaciones procesales posteriores a las ideas socializadoras del proceso han aumentados los poderes del juez con distintos matices, pero aumentos al fin. En Italia, Capelletti, uno de los máximos defensores de las ideas socializadoras, refiriéndose al proceso civil, cuyas ideas son plenamente aplicables al proceso laboral por corresponder a una concepción del proceso en general, afirma, que la total desaparición del poder monopolístico de las partes respecto de las pruebas, es un aspecto, quizás el más importante de la sustracción a las partes del poder de dirección del proceso. Este, no es ya más cosa de las partes, como era el típicamente lento proceso común y el proceso liberal del siglo XIX (en el caso nuestro, el proceso laboral anterior al vigente actualmente). Les queda a las partes (normalmente privadas) el poder exclusivo de elegir entre pedir o no pedir la tutela jurisdiccional de sus (pretendidos) derechos;(...) determinar los límites esenciales de la acción: límites subjetivos (personae), objetivos (petitum), causales (causa petendi) (...). Subsiste, por consiguiente, en sustancia el proceso civil (laboral, en nuestro caso), su núcleo, o si se prefiere su objeto (prozessgegenstand) privado. Pero sobre este núcleo, dejado a la exclusiva potencia de disposición del sujeto (normalmente), el privado, se construye una cáscara, una envoltura, un proceder, que está, en cambio, sustraído a aquella potencia de disposición; una vez instaurado el proceso civil (laboral), el modo, el ritmo, el impulso del proceso mismo se separan de la disponibilidad, inmediata o mediata de las partes ${ }^{31}$.

\footnotetext{
29 Las expresiones en cursiva son de nuestra redacción.

30 Picó I JunOY, Joan, op. cit (n. 2), pp. 220-221.

31 Cappelletti, Mauro, "Iniciative Probatorie del giudice e basi pregiuridiche Della struttura del processo", en: Rivista Diritto Processale, Volumen XXII, pp. 418-419. Padova: CEDAM, 1967.
} 
El otorgamiento de la iniciativa probatoria al órgano jurisdiccional configura una situación de colaboración entre el juez y las partes y no un dominus litis, dirigida al necesario convencimiento judicial acerca de lo discutido en el proceso. Ello no supone, como lo señala acertadamente Guasp Delgado, sustituir la actividad de las partes por la del juez, sino tan solo afirmar su compatibilidad ${ }^{32}$.

El aumento de la iniciativa probatoria del juez produce una atenuación del principio de aportación de parte, pero no es una manifestación del mismo. Por eso, surge como pregunta ¿manifestación de qué principio es? Una primera respuesta sería pensar que constituye una manifestación de los sistemas procesales donde impera el principio inquisitivo, puesto que normalmente en ellos los jueces han tenido poderes o facultades probatorias, pero dicha afirmación la descartamos de plano. Siguiendo a Taruffo, si "inquisitivo" significa, como el origen y la historia del término lo sugieren, un procedimiento en el cual todos los poderes están en manos del tribunal y las partes no tienen ninguna oportunidad de ser oídas, entonces, ningún sistema moderno de litigación civil podría ser apropiadamente definido como inquisitivo $^{33}$. En el mismo orden de ideas, el deber o facultad del juez de disponer pruebas para esclarecer la verdad no significa que nuestro proceso laboral adopte un sistema procesal de tipo inquisitivo. El juez laboral solo esclarece las afirmaciones de hechos controvertidas por las partes, las aclara, disipa dudas; por el contrario, inquirir es indagar, averiguar, investigar hechos que no han sido afirmados necesariamente por las partes, sin sujeción alguna a los hechos aportados por las partes al proceso, introduciendo otros si fuere necesario.

Una respuesta apegada a lo conceptual, nos lleva a decir, entonces, que la iniciativa probatoria del juez es una concreción del principio de investigación de oficio, que normalmente se manifiesta en los procesos donde rige el principio de oficialidad, el cual ha sido definido por Montero Aroca, "como aquel en que la actividad alegatoria y probatoria de las partes no vincula ni limita los poderes de dirección material del juez o tribunal dirigidos a la investigación y prueba de los hechos" 34 . Sin embargo, esta manifestación del principio de investigación de oficio tiene una serie de limitaciones impuestas por el derecho positivo que hacen dudar si realmente es una concreción de dicho principio, producto de los argumentos esgrimidos en el párrafo anterior, pero al menos, es al principio que más se acerca. Por tanto, podría decirse que en materia de pruebas rige el principio de aportación con algunas manifestaciones del principio de investigación de oficio, prevaleciendo aquel sobre este.

Como consecuencia de lo anteriormente expuesto, nos parece equivocada la ubicación de la iniciativa probatoria judicial en la nueva ley procesal laboral, como una manifestación del principio procesal, llamado impulso procesal de oficio. Por una parte, el Código del Trabajo confunde los principios formativos del proceso con los principios formativos del procedimiento, al llevar el párrafo $1^{\circ}$ del capítulo II del Libro V como epígrafe "De los principios formativos del proceso", y después en su primer artículo prescribe: "Los procedimientos del trabajo serán orales(...) Primarán en ellos(...) impulso procesal de oficio, (...)bilateralidad de

32 Guasp Delgado, Jaime, Juez y Hechos en el Proceso Civil. Barcelona: Editorial Bosch, 1943, p. 53.

33 TARUfFO, Michele, "Investigación Judicial y Producción de Prueba por las Partes", en: Revista de Derecho Universidad Austral de Chile, volumen XV, 2003, p. 206. Valdivia: Facultad de Ciencias Jurídicas y Sociales, Universidad Austral de Chile.

34 Citado por CAROCCA PÉREZ, Alex, op. cit. (n. 7), p. 34. 
la audiencia $(. .$.$) ", situación que ha sido clarificada por la doctrina moderna hace ya algunos$ años. Algunos de los principios enumerados en el artículo 425 son del procedimiento, como el impulso procesal de oficio, la inmediación, pues responden a un modo particular de concebir el desarrollo del proceso en su aspecto exterior, es decir, el procedimiento, el cual, es el aspecto externo del proceso. Pero otros principios, como la bilateralidad de la audiencia son principios formativos del proceso, no del procedimiento, siendo común a todo proceso, ya que es inherente a este, si no hay bilateralidad de la audiencia, no hay proceso. Y por otro lado, la ley al señalar algunas de las manifestaciones del principio impulso procesal de oficio en el artículo 429, consagra instituciones que en doctrina claramente no son manifestaciones de dicho principio.

Para poner de manifiesto los errores singularizados, debemos comenzar por señalar que el impulso procesal de oficio significa que una vez concluido uno de los actos procesales del procedimiento, queda en manos del tribunal el deber de pasar al acto procesal siguiente, que la ley prescribe para continuar el desarrollo normal de aquel. No significa, por tanto, que el juez deba realizar actos procesales, ya sean probatorios o de otro carácter, como incorrectamente lo señala el artículo 429 del Código Laboral. Es en virtud del principio de investigación de oficio que el juez tiene iniciativa probatoria, que no aparece mencionado expresamente en la lista de principios, pero ello no importa desconocer que tiene manifestaciones en el nuevo proceso laboral, al menos en materia probatoria, pues el no estar expresamente consagrado no es óbice para negar su manifestación en la ley de proceso laboral, mayormente cuando hay normas que son concreciones de él.

\section{INICIATIVA PROBATORIA JUDICIAL. UNA BREVE REFERENCIA}

La legislación actual en concordancia con las tendencias y legislaciones más avanzadas han aumentado considerablemente las funciones-deberes del juez laboral en materia probatoria.

Para una mejor comprensión, digamos que la iniciativa judicial en materia probatoria puede operar en dos oportunidades. Primero en el momento de proponer pruebas y segundo en la oportunidad de evacuarlas, de ejecutarlas o de practicarlas, si se quiere. En cuanto a la proposición de pruebas por parte de la autoridad judicial, la ley ha sido extremadamente cuidadosa, consciente de los peligros de otorgar una iniciativa deliberada. Por ello, para que pueda operar se deben cumplir una serie de requisitos, algunos de los cuales están en la norma que la regula y otros dispersos en diversos artículos. Es el artículo 429 del Código del Trabajo que reglamenta esta situación, cuando señala:

"Decretará las pruebas que estime necesarias, aun cuando no las hayan ofrecido las partes y rechazará mediante resolución fundada aquellas que considere inconducentes. De esta resolución se podrá deducir recurso de reposición en la misma audiencia”; y el artículo 453 No 9, que dispone: "En la audiencia preparatoria se aplicarán las siguientes reglas:

9) En esta audiencia, el juez de la causa podrá decretar diligencias probatorias, las que deberán llevarse a cabo en la audiencia de juicio". 
A nuestro entender estos artículos son más exigentes que el antiguo artículo 454 del Código del Trabajo, que regulaba las medidas para mejor resolver en el antiguo proceso laboral, pues no solo opera en un tiempo más restringido, sino que, además, debe cumplir con requisitos que son más exigentes. Quizás la experiencia de las medidas para mejor resolver haya llevado al legislador a evitar el abuso que se cometió de aquellas, estableciendo una iniciativa probatoria judicial que proceda en los casos estrictamente necesarios, sin desconocer el carácter público del proceso y el interés de la colectividad en los conflictos laborales, por ello se conservó. Por otro lado, creemos que con esta regulación se hace cargo de algunos de los argumentos esgrimidos en contra de esta iniciativa, evitando conflictos de mayor índole.

En el segundo aspecto, relativo a la intervención judicial en la práctica de la prueba, la tendencia ha sido atribuir al juez el máximo posible de poderes-deberes. Ello como necesaria consecuencia de que el juez en lo que se refiere a los hechos, está colocado en evidente situación de inferioridad frente a las partes y, por consiguiente, debe ser obligado a suplir esa inferioridad mediante un manejo cuidadoso y razonable de la técnica del proceso, como único medio para descubrir la verdad, de la cual solo conoce la apariencia gracias a las afirmaciones interesadas de las partes. Por eso, debe disponer de amplia iniciativa, a fin de calificar preguntas, encauzar interrogatorios, dirigir preguntas a las partes, testigos y peritos, solicitar aclaraciones, ordenar compulsas, dirigir oficios a terceros e instituciones, limitar el número de testigos (artículos 453 y principalmente 454 ambos del Código del Trabjo, regulan en forma detallada la intervención del juez en la producción de los medios de pruebas). Todo esto, como es natural, dentro de la más escrupulosa imparcialidad y sin anticipar cuál vaya a ser la sentencia que en su día dicte ${ }^{35}$. Esto no es más que la consagración positiva de lo que la doctrina en forma unánime viene señalando desde hace mucho tiempo: el aumento de los poderes del juez en torno a la dirección formal del proceso. Los artículos 453 y 454 que regulan la audiencia preparatoria del juicio y la audiencia de juicio, respectivamente, se han ocupado de esto, distinguiendo claramente entre la función del juez en torno a la admisibilidad de las pruebas propuestas por las partes, donde solo son admisibles las pruebas que el juez estime que cumplen con los requisitos legales y los poderes del juez en la práctica de las mismas, en el sentido que hemos señalado anteriormente, los cuales han sido aumentados considerablemente, debiendo el juez presenciar obligatoriamente la producción de todas las pruebas como lo ordena la inmediación.

Sin duda que la inmediación y la oralidad, dos de las reglas técnicas predominantes de los procedimientos laborales, han contribuido considerablemente al aumento de los poderes-deberes del juez en la ejecución de las pruebas, ya que ellas demandan una presencia ininterrumpida del juez en la audiencia de juicio, en donde se rinden las pruebas ofrecidas por las partes, tanto es así, que si el juez que presidió la audiencia no pudiere dictar sentencia, aquella deberá repetirse (artículo 460), pues se entiende que la presencia del juez en la audiencia en que se rinden las pruebas es fundamental para lograr el convencimiento sobre la verdad de las afirmaciones fácticas de las partes. Si este no puede dictar sentencia, lo correcto es que se repita con la asistencia de un juez que compruebe la verdad y a la vez pueda dictar sentencia.

35 Rodríguez URRacA, José, op. cit. (n. 18), p. 134. 


\section{CONCLUSIONES}

A través de diversas disposiciones legales ha quedado demostrado que el legislador laboral tuvo en consideración los principios dispositivo y de aportación de partes al configurar el nuevo proceso laboral. Ello es de gran importancia, dado que los operadores del derecho no solo deben respetar las normas concretas que son manifestaciones de dichos principios, sino que, además, deben ser tomados en consideración al interpretar la normativa procesal laboral, y en general en todas las funciones propias de los principios.

Por otra parte se ha delimitado claramente el campo de aplicación de ambos principios, para evitar toda confusión y opinión errada que se base en ellos. En efecto, ha quedado de manifiesto que la opinión que dice que la iniciativa probatoria debe ser rechazada porque vulnera el principio dispositivo y, por tanto, el derecho de propiedad, es errada. La iniciativa probatoria judicial no vulnera dicho principio, tampoco el de aportación de parte, por el contrario, se complementa perfectamente con este último, siendo este el criterio adoptado por la generalidad de las legislaciones.

Al contrario de lo que creen algunos autores, la iniciativa probatoria judicial es plenamente respetuosa de los derechos de los justiciables, el legislador la ha rodeado de una serie de requisitos que evita toda vulneración de los derechos de propiedad y debido proceso, principalmente ${ }^{36}$.

36 Para un estudio detallado sobre la iniciativa probatoria judicial ver FERNÁNDEZ TOLEDO, Raúl, op. cit. (n. 24), pp. 75-211. 


\section{BIBLIOGRAFÍA}

BAUR, Fritz. "Liberalización y Socialización del Proceso Civil", en: Revista de Derecho Procesal Iberoamericana, Tomos II-III. Madrid, 1972.

Calamandrei, Piero, Instituciones de Derecho Procesal Civil. Buenos Aires: Ediciones Jurídicas Europa-América (EJEA), 1962.

CARnACINI, Tito. "Tutela Jurisdiccional y Técnica del Proceso", en: Revista Facultad de Derecho de Universidad Nacional Autónoma de México, No 12. Ciudad de México: Universidad Nacional Autónoma de México, 1953.

CARnelutti, Francesco. Derecho y Proceso. Napoli: Morando Ediciones, 1958.

Carocca PÉrez, Alex. Manual de Derecho Procesal. Santiago: Editorial LexisNexis, 2003.

CAPElletti, Mauro. "Iniciative Probatorie del giudice e basi pregiuridiche Della struttura del processo", en: $R i-$ vista Diritto Processale, Volumen XXII. Padova: CEDAM, 1967.

Cordón Moreno, Faustino. "En torno a los poderes de dirección del juez civil”, en: Revista de Derecho Privado. Madrid, 1979.

Fernández Toledo, Raúl. Las Facultades y Deberes del Juez en Materia Probatoria en el Proceso Laboral. Análisis Crítico. Santiago: Editorial PuntoLex -Thomson Reuters, 2011.

FAIRÉn GUILLÉN, Víctor. "Para la elaboración de una doctrina general de los principios del procedimiento", en: Anuario de Derecho Civil. Madrid, 1948.

GuAsP Delgado, Jaime. Juez y Hechos en el Proceso Civil. Barcelona: Editorial Bosch, 1943

Lascano, David. "El Principio Dispositivo en el Proceso Moderno”, en: Revista de Derecho Procesal Argentina, Volumen II. Buenos Aires, 1951.

Liebman Enrico, Tulio. "Fondamento del Principio Dispositivo", en: Revista di Diritto Processale. Padova: CEDAM, 1960.

Picó I Junoy, Joan. El Derecho a la Prueba en el Proceso Civil. Barcelona: Editorial José María Bosch Editor S.A., 1996.

Rodríguez URraCA, José. Autoridad del juez y principio dispositivo. Valencia-Venezuela: Universidad de Carabobo, Instituto de Derecho Privado y Comparado, 1968.

TARUfFo, Michele. "Investigación Judicial y Producción de Prueba por las Partes", en: Revista de Derecho Facultad de Derecho Universidad Austral de Chile, Volumen XV. Valdivia: Facultad de Ciencias Jurídicas y Sociales, Universidad Austral de Chile, 2003.

VALDÉs HueCHe, Remberto. "El Proceso. La Imparcialidad. La concepción unitaria del proceso. La Constitución Política y los Tratados de Derechos Humanos”, en: Revista Consejo de Defensa del Estado, No 12. Santiago, 2004. 


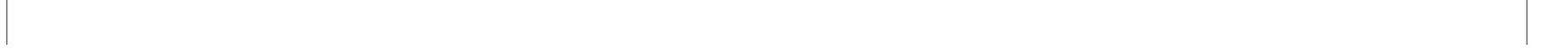

